Article

\title{
The Impact of a Multitasking-Based Virtual Reality Motion Video Game on the Cognitive and Physical Abilities of Older Adults
}

\author{
Xiaoxuan Li ${ }^{1,+} \mathbb{D}$, Kavous Salehzadeh Niksirat ${ }^{1,2,+}+\mathbb{D}$, Shanshan Chen ${ }^{3}$, Dongdong Weng ${ }^{3}$, \\ Sayan Sarcar ${ }^{1,4}\left(\mathbb{D}\right.$ and Xiangshi Ren ${ }^{1, *}$ \\ 1 Center for Human-Engaged Computing, Kochi University of Technology, Kochi 782-8502, Japan; \\ eloisewhirl@gmail.com (X.L.); kavous.salehzadehniksirat@unil.ch (K.S.N.); sayans@slis.tsukuba.ac.jp (S.S.) \\ 2 Department of Information Systems, University of Lausanne, CH-1015 Lausanne, Switzerland \\ 3 School of Optoelectronics, Beijing Institute of Technology, Beijing 100081, China; \\ shanchen0923@gmail.com (S.C.); crgj@bit.edu.cn (D.W.) \\ 4 Faculty of Library Information and Media Science, University of Tsukuba, Tsukuba 305-8550, Japan \\ * Correspondence: ren.xiangshi@kochi-tech.ac.jp \\ + These authors contributed equally to this work.
}

Received: 10 September 2020; Accepted: 30 October 2020; Published: 2 November 2020

\begin{abstract}
This study demonstrates how playing a well-designed multitasking motion video game in a virtual reality (VR) environment can positively impact the cognitive and physical health of older players. We developed a video game that combines cognitive and physical training in a VR environment. The impact of playing the game was measured through a four-week longitudinal experiment. Twenty healthy older adults were randomly assigned to either an intervention group (i.e., game training) or a control group (i.e., no contact). Participants played three 45-min sessions per week completing cognitive tests for attention, working memory, reasoning and a test for physical balance before and after the intervention. Results showed that compared to the control group, the game group showed significant improvements in working memory and a potential for enhancing reasoning and balance ability. Furthermore, while the older adults enjoyed playing the video game, ability enhancements were associated with their intrinsic motivation to play. Overall, cognitive training with multitasking VR motion video games has positive impacts on the cognitive and physical health of older adults.
\end{abstract}

Keywords: cognitive enhancement; motion video game; multitasking; older adults; physical activity; sustainable VR; working memory; attention; reasoning; physical balance

\section{Introduction}

Gameplay is known to reduce cognitive decline [1]. A growing body of evidence shows that video games improve cognitive abilities in older adults [2,3]. The "Brain Age" game was shown to be capable of improving executive functions and processing speeds in older adults after just four weeks of play [3]. Tailoring video games to specific cognitive deficits can be beneficial. "NeuroRacer" [4], a racing game that leverages multitasking training in gameplay, significantly enhances cognition after four weeks of training. Multitasking is the ability to accomplish multiple tasks by frequently switching between tasks [5]. Multitasking is also associated with vulnerable cognitive functions like attention, working memory, and reasoning [6,7].

Most existing studies require older adults to sit while playing but this encourages a sedentary lifestyle which can be detrimental to their general well-being. Conversely, physical activity can positively influence cognitive abilities [8-10]. Rather than considering physical and cognitive training 
separately, the combination of the two may lead to a greater impact on cognitive functions [11-14]. Recent studies $[15,16]$ show that motion video games can produce greater effects on older people in terms of cognitive functions. Such video games can also improve older people's physical abilities like balance [17]. Benefits such as increased confidence, awareness and better balance can increase the life expectancy of older people who are susceptible to falls which often have serious consequences. However, most previous studies used off-the-shelf sports games [18,19] or dancing games [20] and they did not include specific cognitive training or multitasking.

The majority of earlier motion video game studies used Microsoft Kinect@ which has already left the market. Virtual Reality (VR) headsets now dominate motion gameplay because they enable players to better engage with VR environments [21,22] which create better experiences, more positive emotions [23] and a stronger sense of presence [24]. VR gaming experience might also enhance the cognitive efficacy of gameplay $[25,26]$.

To sum up, our literature review showed that most motion video game studies used off-the-shelf video games that do not include cognitive training. Additionally, the existing tailored video games do not include physical training. Therefore, we examine the impact of motion video games tailored for older adults. We are particularly interested in evaluating the efficacy of multitasking motion video games with regard to the cognitive and physical abilities of older adults. We also explore the application of VR technology in terms of playability, usability and as a novel platform for playing motion video games. Thus, we designed a VR motion video game, which aims to enhance various cognitive and physical abilities in older adults and conducted a longitudinal study to investigate its impact on cognitive function and body balance simultaneously.

\section{Materials and Methods}

In this section, we explain our video game design and describe the longitudinal experiment which evaluates its effectiveness.

\subsection{Motion Video Game}

\subsubsection{Gameplay}

We aim at the cognitive enhancement of older adults while increasing their physical activeness in terms of limb movements and walking. We developed simple, enjoyable, stimulus-response gameplay. We chose a farm theme that features an island surrounded by the surging sea, wooden houses and plants. Happy background music enhances the experience. Figure 1a shows the interface. The player views the 3D environment through a Head-Mounted Display (HMD) while holding two controllers that detect hand movements and while wearing two controllers that track ankle movement (Figure 1b).

The game is based on "Whac-A-Mole" gameplay which requires the players to move all limbs to feed animals as they emerge from their holes. In order to help participants learn how to move their bodies, we mapped their body parts to the position of the corresponding holes, e.g., the top-left and the bottom-right holes are mapped to the left arm and the right leg, respectively. 

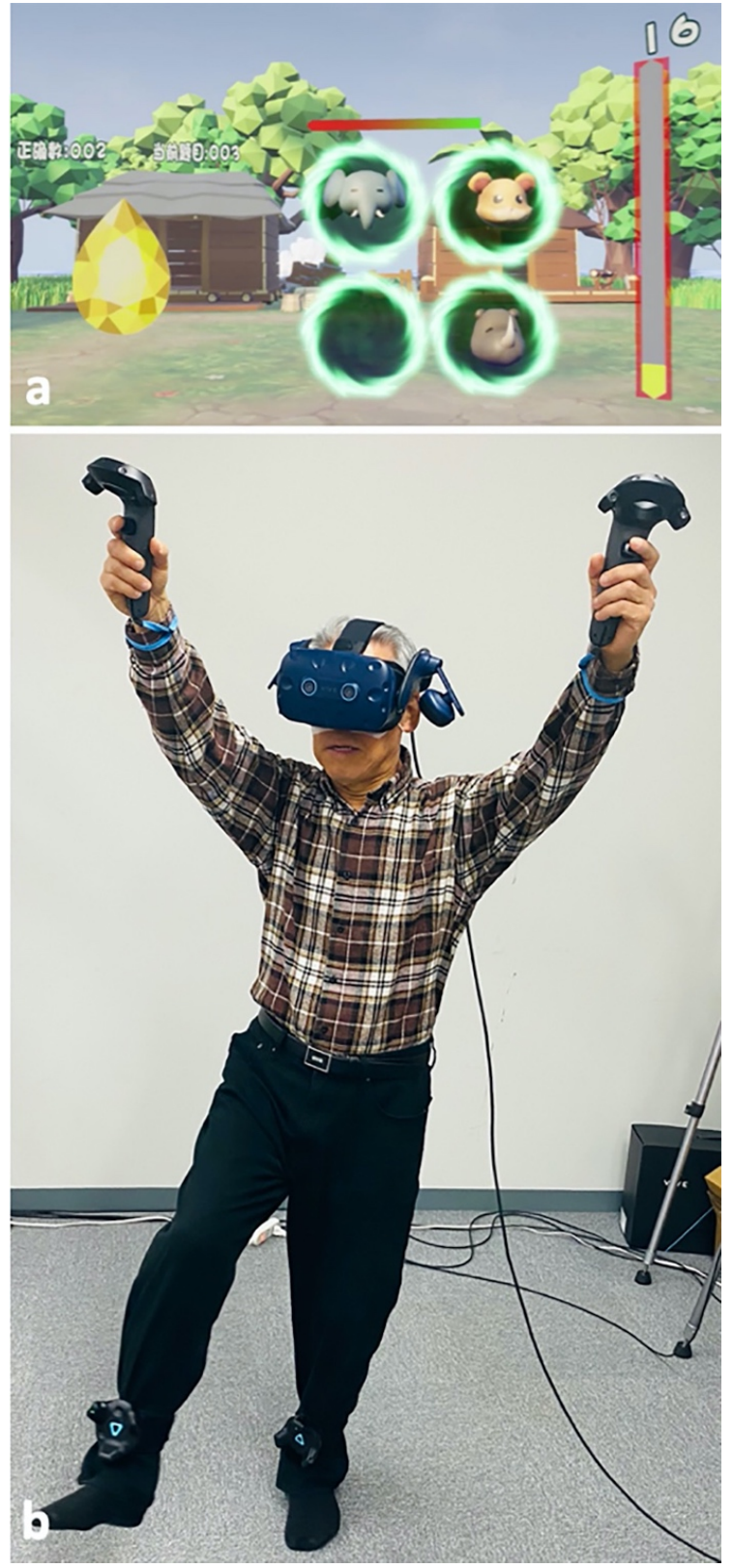

Figure 1. (a) The interface of our motion video game in the virtual reality (VR) environment. (b) An older player wears sensors while playing our game. Body parts are mapped to the position of the corresponding "Whac-A-Mole" hole.

\subsubsection{Multitasking}

We used the multitasking paradigm [5] as an element for cognitive training. To integrate multitasking into Whac-A-Mole gameplay we used a billboard that tells the players which rule to follow. The players switch their attention between the billboard and the emerging animals. Gameplay includes two tasks: (i) Shape task: the billboard randomly shows different shapes (e.g., square, triangle, rectangle) in different colors (e.g., blue, green, yellow). If the shape is a green triangle, the player has to step forward to the right (Figure 2a). Otherwise, the player should step forward to the left (Figure 2b). The player views the virtual environment from his/her body's perspective and controls his/her movement using virtual limbs. (ii) Animal task: after stepping to the right or left, the player needs to raise his/her hands and/or feet to feed the animals. For visual feedback, the game provides colored hints about optional forward step locations (in purple color). If the movement is correct, the color turns to green. 


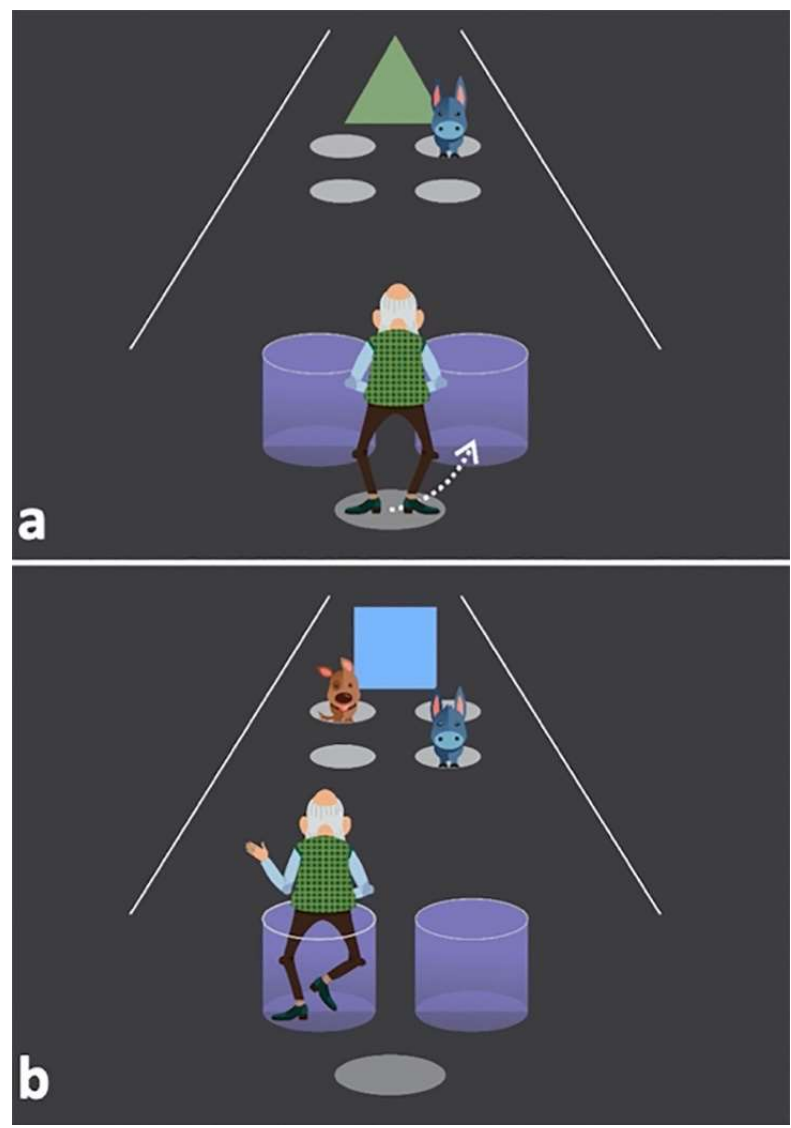

Figure 2. Integrating multitasking and motion. (a) When a green triangle appears, the player has to step forward to the right. (b) When it is not green, the player should step forward to the left.

\subsubsection{Playing procedure}

When the player selects the button on the controller and clicks "Go!", a game difficulty selection interface appears. After choosing the game difficulty, the game interface (a shape task and an animal task) appears. The player can pause the game at any time if discomfort is felt. The game interface includes a time bar (15 min for each level) and it depicts the score that the participant has obtained (the rate of true trials to all trials). It also includes a time progress bar for each game trial which varies according to the game's difficulty level (e.g., $2 \mathrm{~s}$ for level 1, $1.7 \mathrm{~s}$ for level 2, etc.). To promote a sense of competence, appropriate visual and auditory feedback is presented; consecutive successful actions are reported to the players (e.g., "Five Combos!") in real-time. For successive actions such as 5 or 15 consecutive actions, motivational messages such as "good" and "cool" were shown. We followed our earlier work [27] to define the difficulty levels.

\subsection{Experimental Design}

Our mixed design experiment studied the effect of intervention (between-subjects) and time (within-subjects). We compared the game group with the (no contact) control group. Participants in the game group received the VR motion video game as intervention while participants in the control group did not receive any intervention. We compared the results before and after the intervention which lasted four weeks.

\subsubsection{Participants}

We performed a statistical power analysis for mixed-design ANOVA with two groups and $\alpha=0.05$. The analysis indicated that a sample size with twenty participants has $80 \%$ power to detect a small effect (Cohen's $d=0.1$ ). Thus, twenty participants ( 7 males, 13 females, average age: 73.1 years, 
ranging from 65 to 87 years of age, $\mathrm{SD}=7.38$, average years of education: $11.5, \mathrm{SD}=1.7$ ) were recruited. Participants were randomly assigned, 10 to the game group and 10 to the control group. The game group included three males and seven females (average age: 73.8 years, $\mathrm{SD}=7.35$, average education: 11.8 years, $\mathrm{SD}=1.93$ ) while the control group consisted of four males and six females (average age: 72.4 years, $\mathrm{SD}=7.75$, average education: 11.1 years, $\mathrm{SD}=1.45$ ). All participants were healthy having no physical or mental impairments. All participants were able to move freely without any physical burden. None had previous gaming experience. Each was paid $\$ 10$ per hour.

\subsubsection{Procedure}

Participant screening criteria included Mini-Mental State Examination (MMSE) and Geriatric Depression Scale-Short Version-Japanese (GDS-S-J). We excluded participants with MMSE scores of less than 24 and GDS-S-J scores above six. We also excluded participants who had fallen in the last 6 months or who could not walk without assistance. We collected the video game experiences, and we did not recruit anyone with motion video game experience for either the intervention group or for the control group. For practical reasons, we used pseudo-randomization to assign the participants to either the intervention group or the control group. Randomization was based on the order of recruitment. The first five participants were assigned to the intervention group and the second five participants were assigned to the control group. We used the same procedure for groups three and four of the participants. All participants signed letters of consent and were informed about the study's goals. Demographic, health and gaming expertise information were gathered. Game group participants experienced 4-weeks of game training. All participants were told, "Long-term training with video games can improve your cognitive capabilities". They then played the game in practice mode for five minutes. After this, they started the formal experiment. Participants in the game group played three times per week for $45 \mathrm{~min}$ of gameplay each time: three rounds of $15 \mathrm{~min}$ with $5 \mathrm{~min}$ rest between the rounds. Players had a $5 \times 5 \mathrm{~m}^{2}$ area to move in. Participants selected the level of difficulty manually as in our previous work [27] which showed that older adults prefer to choose the level of difficulty so they feel they have more control. Before starting each week of trials, participants were free to change the difficulty level, most increasing by one level each week. Participants in the control group attended the assessments before and after the four-week period but they did not play the video game (i.e., no contact).

\subsubsection{Metrics}

Our main tools were cognitive assessment tools that evaluate working memory, attention and reasoning. We also assessed one-leg balance ability. We used several Player Experience (PX) questionnaires to evaluate game experiences. All participants attended cognitive and physical assessments before and after the four weeks of training. Questionnaires regarding PX were administrated in the 1st week and the 4th week after finishing the game.

Adaptive n-Back Task (n-back). The performance of complex tasks in everyday life requires functional working memory, an area of vulnerability in older adults [28-30]. The Adaptive n-Back task is a behavioral measure of working memory within the larger domain of executive function [31]. In this test, a sequential stream of visual stimuli (letters) was presented at the rate of one at every trial. Each stimulus is typically presented briefly $(0.5 \mathrm{~s})$ with a substantial delay of $2 \mathrm{~s}$ between each to ensure that working memory is sufficiently taxed. The whole task tool around $20 \mathrm{~min}$ and included 20 blocks, where each block contained 20 sequentially presented stimuli trials. Participants were asked to identify whether a current stimulus (e.g., the letter B) was the same as one that appeared in previous $\mathrm{n}$ trials. In the adaptive test, $\mathrm{n}$ had a variable value that changed at times, and the task complexity (i.e., $n$-back level) was adjusted according to each participant's performance. The larger $n$ becomes, the more demand is placed on working memory (i.e., it adds greater cognitive load). The "total number of trials" for each $\mathrm{n}$ was used as the primary measure of working memory. It is worth mentioning that the total number of 1-back and 2-back trials was fixed so that if one became larger, the other became 
smaller. Therefore, accomplishing more 2-back trials in a cognitive test lead to having less 1-back trials in the same test indicating a higher capacity of working memory, vice versa. "Response time" and "accuracy" were also computed.

Raven's Standard Progressive Matrices (SPM). Reasoning ability, an important aspect of advanced human cognitive functioning, tends to decline with age. We used Raven's Standard Progressive Matrices (SPM) [32] which is widely used to evaluate the reasoning ability of older adults [33,34]. SPM is comprised of five sets (A to E) of 12 items each (e.g., A1 through A12), items within a set becoming increasingly difficult, requiring an ever-greater cognitive capacity to encode and analyze information. In each test item, the participant is asked to identify the missing element that completes a pattern. Performance is assessed via "accuracy".

Attention Network Task (ANT). Attention, which declines with aging, nevertheless plays a pivotal role in information processing [35]. We applied the Attention Network Test (ANT), a tool that is widely used in neuropsychological studies to assess the efficiency of attention [36-38]. In each trial, a spatial cue was presented followed by an array of five arrows presented at either the top or the bottom of the screen. ANT requires participants to determine whether a central arrow points left or right. "Response time" was used as the primary measure of attention. "Accuracy" was also computed.

One-leg Standing Balance Test (OLSBT). One-Leg Balance ability, an important predictor of falls in older adults [39], correlates with age [40]. OLSBT, a widely used evaluation tool [41,42] includes two conditions: eyes-open and eyes-closed, all balancing activities being timed with a digital stopwatch. Participants stood on one leg (whichever felt more comfortable), flexed the other knee so the foot cleared the floor, and balanced on one leg for as long as possible, arms by their sides. Timing began when the foot was raised. Balance "time" was used as the primary metric.

Positive Affect Negative Affect Schedule (PANAS). To measure player experience, including the positive and negative affects during the game, we used PANAS [43]. Participants were asked to agree to 20 emotional adjectives, ranging from 1 (very slight or not at all) to 5 (extreme) on a Likert-scale. Half of the adjectives were positive (e.g., "active") and half were negative (e.g., "guilty"). Ratings were merged to create a composite score for negative affect and one for positive affect.

Intrinsic Motivation Inventory (IMI). Intrinsic Motivation was assessed using the 18-item IMI [44], which is widely used to evaluate experiences with video games [45]. Nineteen items were rated on a 7-point Likert-scale, ranging from 1 (not at all true) to 7 (very true), e.g., "I thought this game was quite enjoyable" and "This game was fun to do".

Player Experience of Needs Satisfaction (PENS). PENS evaluates needs satisfaction in the game experience from the perspective of Self-Determination Theory [46]. It consists of five dimensions: competence, autonomy, relatedness, presence, and intuitive controls, e.g., "I feel very capable and effective when playing", "I feel competent at the game" [45]. A 7-point Likert scale was applied.

Observation. We observed the participants' gameplay by asking them questions at the end of the experiment: (i) What do you think about the game style, background music and other game elements? (ii) How do you feel about playing this game? (iii) Did you feel dizzy while playing, or tired? (iv) Would you recommend this game to your friends?

\section{Results}

Statistical analyses were performed using SPSS ver. 25 (SPSS, Chicago, IL, USA). Statistical power analysis was performed using $\mathrm{G}^{*}$ Power statistical tool [47]. Data were analyzed using $2 \times 2 \mathrm{mixed}$ ANOVA comparing time (within-subjects: pre vs. post) and intervention (between-subjects: game vs. no-contact). The relationship between game experience with intervention effect was evaluated using Pearson Correlation. The IMI and PENS data between the 1st and 4th weeks were analyzed using a paired t-test. The significance level was set at $\alpha=0.05$. 


\subsection{Cognitive Assessment}

\subsubsection{Working Memory (n-back)}

Figure 3 shows the number of n-back trials. For the number of 2-back trials, we found a significant main effect for time $(\mathrm{F}(1,17)=25.66, p<0.001, \eta \mathrm{p} 2=0.588)$, and a significant interaction effect between time and intervention $(\mathrm{F}(1,18)=6.898, p<0.05, \eta \mathrm{p} 2=0.277)$. There was no main effect for intervention. The results show that video game training increased the number of 2-back trials significantly $(p<0.001)$ from 143.54 in pre-test $(S D=92.43)$ to 194.46 in post-test $(S D=96.47)$, while there was no significant difference between pre-test and post-test in the control group.

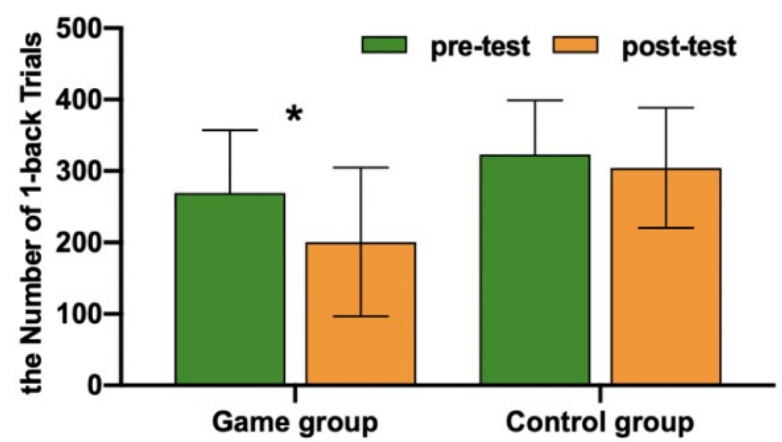

(a)

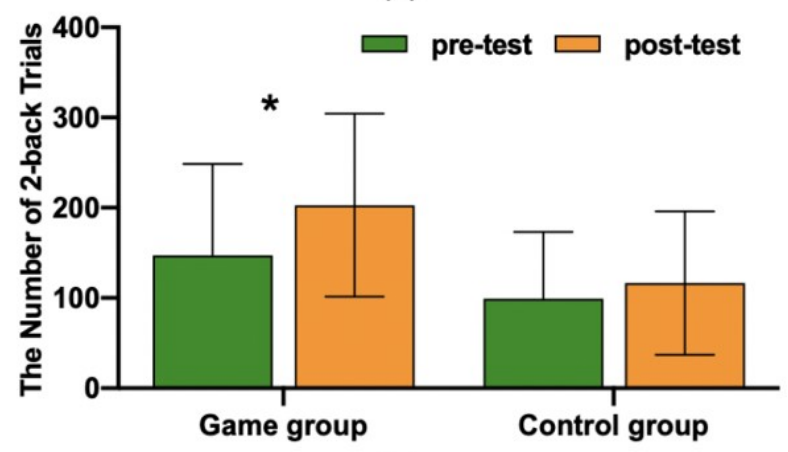

(b)

Figure 3. The number of (a) 1-back and (b) 2-back trials. The error bars indicate \pm SE. The asterisks $\left(^{*}\right)$ indicate a significant difference at $95 \%$ confidence interval.

For the number of 1-back trials, we found a significant main effect for intervention $(F(1,17)=5.45$, $p<0.05, \eta p 2=0.243)$, a significant main effect for time $(\mathrm{F}(1,17)=50.15, p<0.001, \eta p 2=0.747)$, and a significant interaction effect between time and intervention $(\mathrm{F}(1,17)=17.774, p<0.001, \eta \mathrm{p} 2=0.511)$. The results show that video game training decreased the number of 1-back trials significantly $(p<0.001)$ from 269.50 in pre-test $(S D=87.57)$ to 200.70 in post-test $(S D=103.95)$, while there was no significant difference between pre-test and post-test in the control group.

\subsubsection{Reasoning (SPM)}

Figure 4 shows the accuracy of SPM tests. For the accuracy of SPM tests, we found a main effect for time $(\mathrm{F}(1,18)=8.56, p<0.01, \eta \mathrm{p} 2=0.322)$. However, there was no effect on intervention or interaction effect between time and intervention. The results show that video game training improved accuracy in the SPM test significantly $(p<0.05)$ from $74.67 \%$ in pre-test $(\mathrm{SD}=18.42)$ to $82.10 \%$ in post-test $(\mathrm{SD}=13.27$ ), while we did not find a significant difference for the control group (pre-test $=72.50 \%$, post-test $=76.80 \%, p=0.189$ ). 


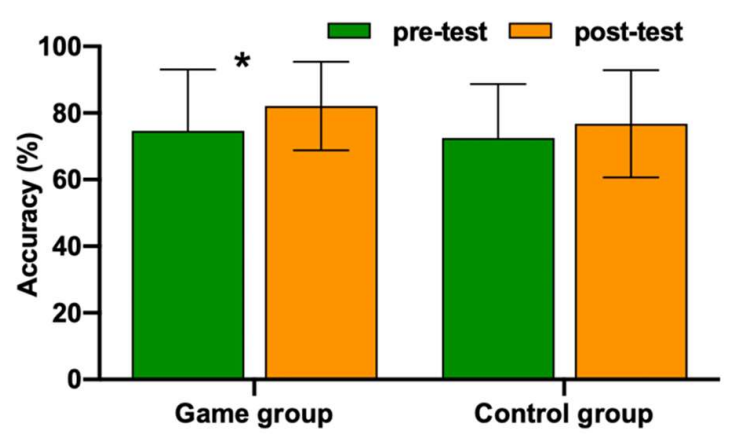

Figure 4. Accuracy for Standard Progressive Matrices (SPM) test in percentage (\%). The error bars indicate \pm SE. The asterisk $\left(^{*}\right)$ indicates a significant difference at $95 \%$ confidence interval.

\subsubsection{Attention (ANT)}

For the response time for ANT test, our analysis revealed a significant main effect for time $(\mathrm{F}(1,18)=40.74, p<0.001, \eta \mathrm{p} 2=0.694)$. However, there was no main effect for intervention or interaction effect between time and intervention. The ANT test results show that video game training decreased the response time significantly $(p<0.001)$ from 904.00 in pre-test $(S D=129.46)$ to 825.91 in post-test $(\mathrm{SD}=136.32)$. However, the response time also significantly decreased in the control group. To sum, the results for response time are inconclusive. We did not find any significant improvement in accuracy.

\subsection{Physical Assessment}

\section{Balance (OLSBT)}

Figure 5 shows the one-leg balance time (OLSBT) results. In the open-eyes conditions, we found a significant main effect for time $(\mathrm{F}(1,18)=4.816, p<0.05, \eta \mathrm{p} 2=0.211)$. There was no effect for intervention or interaction effect between time and intervention. The results show that video game training significantly increased one-leg balance time for the open-eyes condition $(p<0.05)$ from $58,026$ milliseconds in the pre-test $(S D=23,641)$ to 72,402 milliseconds in post-test ( $S D=27,120)$, while there was no significant difference in the control group.

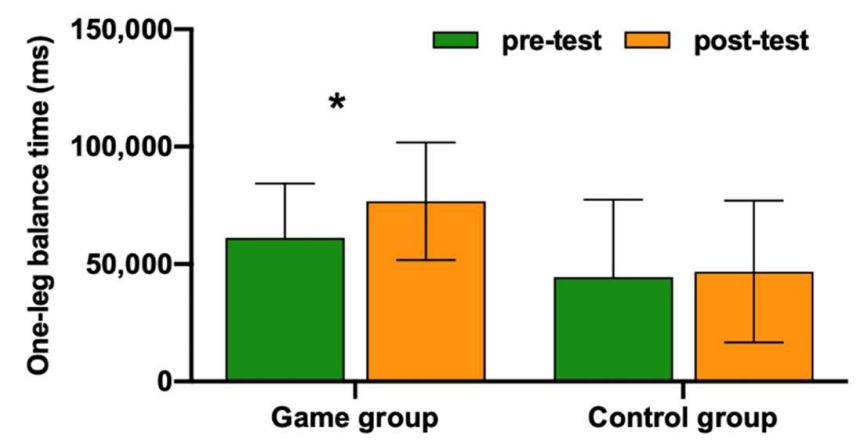

Figure 5. One-leg balance time for the open-eyes condition in milliseconds (ms). The error bars indicate \pm SE. The asterisk $\left(^{*}\right)$ indicates a significant difference at $95 \%$ confidence interval.

\subsection{Player Experience (PX)}

\subsubsection{IMI and PENS}

The total score for IMI and PENS did not reveal any significant difference between the 1st and 4th weeks of gameplay. The results show that during the 4 weeks of video game training, our game provided a good game experience and there had been no change in intrinsic motivation and needs 
satisfaction. This finding suggests that our motion video game can be used for the long-term training of older adults.

\subsubsection{IMI and Cognitive Enhancement}

We found that there is a negative correlation $(\mathrm{r}=-0.566, p<0.05)$ between the average IMI and improvement in response time for ANT. The results show that the higher the IMI score, the more improvement there was in ANT response time. We also found that there is a positive correlation $(\mathrm{r}=0.585, p<0.05)$ between the average IMI and improvement in accuracy for SPM. These results indicate that elderly players who were motivated by the gameplay received greater mental benefits.

\subsubsection{PANAS and Physical Enhancement}

We found a positive correlation $(r=0.716, p<0.05)$ between the post score positive affect in PANAS and improvement in one-leg balance time in the open-eyes condition. The results show that the higher the positive affect, the longer the balance time becomes. This finding suggests that elderly players enjoyed the gameplay and improved physical balance.

\subsubsection{Participant Feedback}

Most participants reported they were satisfied with the gameplay. Participants reported: "by playing this game, I feel my body has become better than before. My blood pressure usually rises at this time every year, but it has dropped this year. It is probably due to playing this game." [P1]; "the game combines the body and brain and it is a good stimulus" [P2]; "I like VR motion games because the body moves and feels better after playing the game" [P3]; "If I play games that move the body, I will play longer" [P6]. Two participants reported inconvenience carrying the VR head-mounted display: "the helmet is a bit heavy. It is easy to make mistakes due to incorrectly wearing the VR device during training, but I feel very happy" [P7].

Almost all of the participants in the intervention group (over 8/10) liked our farm-themed game style; they thought it was cute and entertaining. We also observed that when some participants first entered the VR game environment they were very surprised, happy, and they found it very interesting.

\section{Discussion}

Our study integrated cognitive and physical training in the form of a multitasking-based VR motion video game. A longitudinal experiment revealed that training with our motion video game is a promising and effective approach to increasing the cognitive and physical wellbeing of older adults. Our findings show that the motion video game improves the working memory of healthy older adults. We did not find a positive impact on attention. The motion video game also showed a potential for enhancing reasoning ability and balance. We found that older adults soon developed favorable attitudes to VR technology.

Working memory temporarily stores and processes information, and its agility leads to better video game performance. The video game not only requires players to remember instructions (e.g., the shape and the locations of animals), it also requires to remember actions that correspond to the game instructions (e.g., moving right or left). Our findings suggest that four weeks of motion video game training increased the number of 2-back trials and decreased the number of 1-back trials. This indicates that the participants in the intervention group did more 2-back and fewer 1-back trials after the intervention, but the participants in the control group did not experience this phenomenon. Thus, given that the 2-back trials are more demanding on memory than the 1-back trials, our video game training helped improve the participants' working memory. Among the cognitive skills, working memory made the most significant gains from motion video game training, where we found small to moderate effect sizes for working memory (2-back: Cohen's d $=0.27$; 1-back: Cohen's $d=0.51$ ), but we could not find a significant interaction effect for reasoning or attention. This is congruent with existing studies showing that motion video games can facilitate executive functions. For example, 
a study by Eggenberger et al. [20] found that a VR dancing game can improve the working memory, while walking on the treadmill has no such effect.

Reasoning is a higher-order executive function. It includes the ability to figure out the abstract relations underlying analogies. During gameplay, players need to better cope with larger multitasking requirements compared to individual tasks; they need to integrate multiple tasks that contain different types of stimuli, all being necessary to the successful execution of the task. We found a significant main effect for time with reasoning. This may relate to the improvement in working memory. Without working memory, reasoning ability would not be possible, and it is essential to our ability to understand the connections between seemingly unrelated things and to separate elements from a whole [48]. This finding shows that the intervention has promising effects on reasoning as measured by SPM. However, given the lack of a significant interaction effect, a larger study is required to fully test this hypothesis. The implications and impacts of motion game training on higher-order executive functions deserve more attention; future studies should conduct more extensive assessments by investigating their effects on advanced cognitive functions such as problem-solving and planning.

Attention refers to the ability to concentrate on specific stimuli. If players have more attention resources, they will be inclined to (re)focus their attention on the current task. During the multitasking process, players have to assign their attention to different tasks, feedback and reactions, they are also required to switch their attention and allocate cognitive resources between different cognitive tasks and different motor reactions. Unexpectedly, we did not find significant effects for attention; this is not consistent with some previous studies [20,49]. For example, in the study of Eggenberger et al. [20], simultaneous cognitive-physical training caused significant improvement in attention. However, other studies revealed no significant results for attention [50,51]. For instance, in a study by Van het Reve and de Bruin [51], which included three months of cognitive and physical attention, training did not lead to any significant improvement in attention. One could speculate that a training period of four weeks might not have been enough to induce distinct changes in attention. The latest review article [13] showed that training times for exergames ranged from 6-12 weeks, with an average of 11 weeks.

The results of physical balance show that motion game players outperform the participants in the control group. This shows the potential for motion video games to improve physical balance. Our result is consistent with the study of motor-cognitive dual-task training as a method of improving physical balance [52]. Dual-tasking ability refers to the performance of the simultaneous motor and cognitive tasks (e.g., walking and talking simultaneously). Our game also includes continuous motor and cognitive tasks, where players are required to continuously perform not only multiple cognitive game tasks but also corresponding physical tasks. However, given the lack of a significant interaction effect, these results could be considered with caution. As a future direction, we are interested to see how long-term play of the motion video game could decrease the tendency to fall for older adults.

At present, studies on combined approaches to VR can be classified into two categories. The first category is the separation of cognitive and physical activities, such as counting while riding a bicycle. The second category is the combination of motion games and cognitive stimulation in VR. Our game belongs to the latter category. In our game, bodily movement needs to adapt to changes in simultaneous cognitive tasks; this obviously requires more cognitive resources and control processes. Our study shows that the players can adapt well to our game; it provides empirical evidence that combined cognitive and physical training can be incorporated into VR games for healthy older adults. Regarding the overall game experience, players enjoyed our game, including game dynamics, theme, music, etc. Participants in particular liked the physical movement as they felt the exercise to be more beneficial to their health. This finding showed that bodily movement is an engaging factor for older adults that can motivate them to prolong training. We also found that improvements in cognitive abilities are related to the participants' intrinsic motivation for gameplay. This is consistent with the studies [53,54] that confirm that motivation for training yields cognitive benefits. This may be due to the fact that the immersion and presence evoked by VR environments increases motivation, leads to positive reactions, and produces more behavioral effort. According to a previous study [26], 
player motivation may be triggered by the game itself or by the immersive feeling inspired by VR technology. During the four weeks of game training, intrinsic motivation remained almost constant. This could indicate that VR is a promising technology to improve cognition in the long-term since it inspires a sustainable commitment to long-term participation. Future research should investigate how player motivation is related to cognitive enhancement and how it can be manifested in a specific cognitive domain.

Our study is subject to several limitations: (1) The sample size limits the ability to generalize our results. While our power analysis indicated $80 \%$ power to detect a small effect, to reach higher power we require more participants (e.g., 32 participants for $95 \%$ power). (2) For practical reasons, we used the pseudo-randomization procedure for grouping. Although our participants were well-balanced into two groups based on their age, gender, and level of education, we admit that such randomization methods may cause potential bias in the results. (3) We compared the game group to the control group which did not receive any intervention. Thus, in the current experimental design, it is not possible to determine which factors in the game are responsible for respective improvements (e.g., VR, multitasking, physical activity). Further research is required to systematically analyze these effects (e.g., comparing VR versus non-VR groups, motion versus sedentary groups, and multitasking versus single-tasking groups). (4) Following our previous findings [27], we allowed the participants to select the game difficulty manually instead of the automatic approach. Some participants might choose levels that were beneath their abilities and they could experience less intense and challenging gameplay; this is likely to result in less benefit from the training. Since this could have an impact on the cognitive benefit of training, future research should study how the challenge level in the game should be adapted to each participant's ability without diminishing their sense of autonomy.

In summary, this paper describes a longitudinal study aimed at exploring the health effects on older adults of long-term participation in tailored motion video games. Our results suggest that multitasking-based VR motion video games offer a promising approach to enhancing the cognitive and physical health of the aging population. Our work also illustrates the feasibility of using motion video games to train the cognitive and physical abilities of older adults in VR environments. This work can provide a reference for the development of novel digital health interventions suitable for long-term training. We believe our study is an important contribution to the development of VR motion video games for the wellbeing of the elderly and it can contribute to healthy aging and the sustainable development of societies. We expect this work will inspire further significant inquiries and results.

Author Contributions: Conceptualization, X.R., K.S.N. and D.W.; Methodology, K.S.N., X.L. and S.C.; Software, D.W.; Validation, X.L.; Formal Analysis, X.L. and K.S.N.; Resources, K.S.N. and X.L.; Data Curation, X.L.; Writing-Original Draft Preparation, X.L., K.S.N., S.S., and X.R.; Writing-Review and Editing, X.L., K.S.N., S.S. and X.R.; Visualization, X.L.; Supervision, K.S.N. and X.R.; Project Administration, X.R.; Funding Acquisition, X.R. All authors have read and agreed to the published version of the manuscript.

Funding: This research received no external funding.

Acknowledgments: We thank members of the Center for Human-Engaged Computing in Kochi University of Technology for their support. We wish to thank Zhihang Guo and Lijing Zhou for their help in system development, Takaaki Kubo, Jiayuan Geng and Yanyin Zhou for their help in conducting experiments. We also wish to thank Huamao Peng and Ting Jiang for their valuable comments.

Conflicts of Interest: The authors declare no conflict of interest.

\section{References}

1. Altschul, D.M.; Deary, I.J. Playing Analog Games Is Associated With Reduced Declines in Cognitive Function: A 68-Year Longitudinal Cohort Study. J. Gerontol. B Psychol. Sci. Soc. Sci. 2019, 75, 474-482. [CrossRef] [PubMed]

2. Lee, H.K.; Kent, J.D.; Wendel, C.; Wolinsky, F.D.; Foster, E.D.; Merzenich, M.M.; Voss, M.W. Home-Based, Adaptive Cognitive Training for Cognitively Normal Older adults: Initial Efficacy Trial. J. Gerontol. B Psychol. Sci. Soc. Sci. 2019, 75, 1144-1154. [CrossRef] 
3. Nouchi, R.; Taki, Y.; Takeuchi, H.; Akitsuki, Y.; Shigemune, Y.; Sekiguchi, A.; Kotozaki, Y.; Tsukiura, T.; Yomogida, Y. Brain training game improves executive functions and processing speed in the elderly: A randomized controlled trial. PLoS ONE 2012, 7, e29676. [CrossRef] [PubMed]

4. Anguera, J.A.; Boccanfuso, J.; Rintoul, J.L.; Al-Hashimi, O.; Faraji, F.; Janowich, J.; Kong, E.; Larraburo, Y.; Rolle, C.; Johnston, E. Video game training enhances cognitive control in older adults. Nature 2013, 501, 97-101. [CrossRef] [PubMed]

5. Delbridge, K.A. Individual Differences in Multi-Tasking Ability: Exploring a Nomological Network. Unpublished Doctoral Dissertation, Michigan State University, East Lansing, USA, 2000. Available online: https://www.researchgate.net/publication/33710097 (accessed on 31 October 2020).

6. Colom, R.; Martínez-Molina, A.; Shih, P.C.; Santacreu, J. Intelligence, working memory, and multitasking performance. Intelligence 2010, 38, 543-551. [CrossRef]

7. Konig, C.J.; Buhner, M.; Murling, G. Working memory, fluid intelligence, and attention are predictors of multitasking performance, but polychronicity and extraversion are not. Hum. Perform. 2005, 18, 243-266. [CrossRef]

8. $\quad$ Bherer, L.; Langeard, A.; Kaushal, N.; Vrinceanu, T.; Desjardins-crépeau, L.; Langlois, F.; Kramer, A.F. Physical Exercise Training Effect and Mediation Through Cardiorespiratory Fitness on Dual-Task Performances Differ in Younger-Old and Older-Old Adults. J. Gerontol. B Psychol. Sci. Soc. Sci. 2019, gbz66. [CrossRef] [PubMed]

9. Chapman, S.B.; Aslan, S.; Spence, J.S.; DeFina, L.F.; Keebler, M.W.; Didehbani, N.; Lu, H. Shorter term aerobic exercise improves brain, cognition, and cardiovascular fitness in aging. Front. Aging Neurosci. 2013, 5, 75. [CrossRef]

10. Wayne, P.M.; Walsh, J.N.; Taylor-Piliae, R.E.; Wells, R.E.; Papp, K.V.; Donovan, N.J.; Yeh, G.Y. Effect of Tai Chi on cognitive performance in older adults: Systematic review and meta-analysis. J. Am. Geriatr. Soc. 2014, 62, 25-39. [CrossRef] [PubMed]

11. Besombes, N.; Maillot, P. Body Involvement in Video Gaming as a Support for Physical and Cognitive Learning. Games Cult. 2020, 15, 565-584. [CrossRef]

12. Lauenroth, A.; Ioannidis, A.E.; Teichmann, B. Influence of combined physical and cognitive training on cognition: A systematic review. BMC Geriatr. 2016, 16, 141. [CrossRef] [PubMed]

13. Stojan, R.; Voelcker-Rehage, C. A Systematic Review on the Cognitive Benefits and Neurophysiological Correlates of Exergaming in Healthy Older Adults. J. Clin. Med. 2019, 8, 734. [CrossRef] [PubMed]

14. Zhu, X.; Yin, S.; Lang, M.; He, R.; Li, J. The more the better? A meta-analysis on effects of combined cognitive and physical intervention on cognition in healthy older adults. Ageing Res. Rev. 2016, 31, 67-79. [CrossRef] [PubMed]

15. Barcelos, N.; Shah, N.; Cohen, K.; Hogan, M.J.; Mulkerrin, E.; Arciero, P.J.; Cohen, B.D.; Kramer, A.F.; Anderson-Hanley, C. Aerobic and Cognitive Exercise (ACE) pilot study for older adults: Executive function improves with cognitive challenge while exergaming. JINS J. Int. Neuropsychol. Soc. 2015, 21, 768. [CrossRef]

16. Monteiro-Junior, R.S.; Vaghetti, C.A.O.; Nascimento, O.J.M.; Laks, J.; Deslandes, A.C. Exergames: Neuroplastic hypothesis about cognitive improvement and biological effects on physical function of institutionalized older persons. Neural Regener. Res. 2016, 11, 201-204. [CrossRef]

17. Kayama, H.; Okamoto, K.; Nishiguchi, S.; Yamada, M.; Kuroda, T.; Aoyama, T. Effect of a Kinect-based exercise game on improving executive cognitive performance in community-dwelling elderly: Case control study. J. Med Internet Res. 2014, 16, e61. [CrossRef]

18. Guimarães, A.V.; Barbosa, A.R.; Meneghini, V. Active videogame-based physical activity vs. aerobic exercise and cognitive performance in older adults: A randomized controlled trial. J. Phys. Educ. Sport 2018, 18, 203-209. Available online: http://efsupit.ro/images/stories/martie2018/Art\%2026.pdf (accessed on 31 October 2020).

19. Maillot, P.; Perrot, A.; Hartley, A. Effects of interactive physical-activity video-game training on physical and cognitive function in older adults. Psychol. Aging 2012, 27, 589-600. [CrossRef]

20. Eggenberger, P.; Schumacher, V.; Angst, M.; Theill, N.; de Bruin, E.D. Does multicomponent physical exercise with simultaneous cognitive training boost cognitive performance in older adults? A 6-month randomized controlled trial with a 1-year follow-up. Clin. Interv. Aging 2015, 10, 1335-1349. [CrossRef]

21. García-Betances, R.I.; Arredondo Waldmeyer, M.T.; Fico, G.; Cabrera-Umpiérrez, M.F. A succinct overview of virtual reality technology use in Alzheimer's disease. Front. Aging Neurosci. 2015, 7, 80. [CrossRef] 
22. Laver, K.; George, S.; Thomas, S.; Deutsch, J.E.; Crotty, M. Cochrane review: Virtual reality for stroke rehabilitation. Eur. J. Phys. Rehabil. Med. 2012, 48, 523-530. [CrossRef]

23. Tan, C.T.; Leong, T.W.; Shen, S.; Dubravs, C.; Si, C. Exploring gameplay experiences on the Oculus Rift. In Proceedings of the 2015 Annual Symposium on Computer-Human Interaction in Play, London, UK, 5-7 October 2015; pp. 253-263. [CrossRef]

24. Shelstad, W.J.; Smith, D.C.; Chaparro, B.S. Gaming on the rift: How virtual reality affects game user satisfaction. Proc. Hum. Factors Ergon. Soc. Annu. Meet. 2017, 61, 2072-2076. [CrossRef]

25. Anderson-Hanley, C.; Arciero, P.J.; Brickman, A.M.; Nimon, J.P.; Okuma, N.; Westen, S.C.; Merz, M.E.; Pence, B.D.; Woods, J.A.; Kramer, A.F. Exergaming and older adult cognition: A cluster randomized clinical trial. Am. J. Prev. Med. 2012, 42, 109-119. [CrossRef] [PubMed]

26. Huang, K.-T. Exergaming executive functions: An immersive virtual reality-based cognitive training for adults aged 50 and older. Cyberpsychol. Behav. Soc. Netw. 2019, 23, 143-149. [CrossRef] [PubMed]

27. Salehzadeh Niksirat, K.; Silpasuwanchai, C.; Ren, X.; Wang, Z. Towards cognitive enhancement of the elderly: A ux study of a multitasking motion video game. In Proceedings of the $2017 \mathrm{CHI}$ Conference Extended Abstracts on Human Factors in Computing Systems, Denver, CO, USA, 6-11 May 2017; pp. 2017-2024. [CrossRef]

28. Baddeley, A. Working memory. Science 1992, 255, 556-559. [CrossRef]

29. Baddeley, A.D.; Hitch, G. Working memory. Psychol. Learn. Motiv. 1974, 8, 47-89. [CrossRef]

30. Susanne, M.J.; Martin, J.; Walter, J.P.; Beat, M. The concurrent validity of the N-back task as a working memory measure. Memory 2010, 18, 394-412. [CrossRef]

31. Heinzel, S.; Schulte, S.; Onken, J.; Duong, Q.L.; Riemer, T.G.; Heinz, A.; Kathmann, N.; Rapp, M.A. Working memory training improvements and gains in non-trained cognitive tasks in young and older adults. Aging Neuropsychol. Cogn. 2014, 21, 146-173. [CrossRef]

32. Burke, H.R. Raven's Progressive Matrices: Validity, Reliability, and Norms. J. Psychol. 1972, 82, $253-257$. [CrossRef]

33. Raven, J.H. Raven, J.H. Raven Progressive Matrices. In Handbook of Nonverbal Assessment; Springer: Boston, MA, USA, 2003. Available online: https://link.springer.com/chapter/10.1007\%2F978-1-4615-0153-4_11 (accessed on 31 October 2020).

34. Kaplan, R.M.; Saccuzzo, D.P. Standardized tests in education, civil service, and the military. Psychol. Test. Princ. Appl. 2009, 7, 325-327. Available online: https://books.google.co.jp/books?id=4TIeNj-MlrsC\& dq=Psychological+Testing:+Principles,+ Applications,, and + Issues $+2009+7 \&$ hl=zhCN\&source=gbs navlinks_s (accessed on 31 October 2020).

35. Harada, C.N.; Love, M.C.N.; Triebel, K.L. Normal cognitive aging. Clin. Geriatr. Med. 2013, $29,737-752$. [CrossRef]

36. Fan, J.; McCandliss, B.D.; Sommer, T.; Raz, A.; Posner, M.I. Testing the efficiency and independence of attentional networks. J. Cogn. Neurosci. 2002, 14, 340-347. [CrossRef]

37. MacLeod, J.W.; Lawrence, M.A.; McConnell, M.M.; Eskes, G.A.; Klein, R.M.; Shore, D.I. Appraising the ANT: Psychometric and theoretical considerations of the Attention Network Test. Neuropsychology 2010, 24, 637. [CrossRef] [PubMed]

38. Westlye, L.T.; Grydeland, H.; Walhovd, K.B.; Fjell, A.M. Associations between Regional Cortical Thickness and Attentional Networks as Measured by the Attention Network Test. Cereb. Cortex 2011, 21, 345-356. [CrossRef]

39. Vellas, B.J.; Wayne, S.J.; Romero, L.; Baumgartner, R.N.; Rubenstein, L.Z.; Garry, P.J. One-leg balance is an important predictor of injurious falls in older persons. J. Am. Geriatr. Soc. 1997, 45, 735-738. [CrossRef] [PubMed]

40. Bohannon, R.W.; Larkin, P.A.; Cook, A.C.; Gear, J.; Singer, J. Decrease in timed balance test scores with aging. Phys. Ther. 1984, 64, 1067-1070. [CrossRef] [PubMed]

41. Briggs, R.C.; Gossman, M.R.; Birch, R.; Drews, J.E.; Shaddeau, S.A. Balance performance among noninstitutionalized elderly women. Phys. Ther. 1989, 69, 748-756. [CrossRef]

42. Vellas, B.J.; Rubenstein, L.Z.; Ousset, P.J.; Faisant, C.; Kostek, V.; Nourhashemi, F.; Allard, M.; Albarede, J.L. One-leg standing balance and functional status in a population of 512 community-living elderly persons. Aging Clin. Exp. Res. 1997, 9, 95-98. [CrossRef] 
43. Watson, D.; Clark, L.A. The PANAS-X: Manual for the Positive and Negative Affect Schedule-Expanded Form; University of Iowa: Iowa City, IA, USA, 1994. [CrossRef]

44. Ryan, R.M. Control and information in the intrapersonal sphere: An extension of cognitive evaluation theory. J. Personal. Soc. Psychol. 1982, 43, 450-461. [CrossRef]

45. Ryan, R.M.; Rigby, C.S.; Przybylski, A. The motivational pull of video games: A self-determination theory approach. Motiv. Emot. 2006, 30, 344-360. [CrossRef]

46. Deci, E.L.; Ryan, R.M. The "what" and "why" of goal pursuits: Human needs and the self-determination of behavior. Psychol. Inq. 2000, 11, 227-268. Available online: https://www.tandfonline.com/doi/abs/10.1207/ S15327965PLI1104_01 (accessed on 31 October 2020). [CrossRef]

47. Faul, F.; Erdfelder, E.; Buchner, A.; Lang, A.-G. Statistical power analyses using G* Power 3.1: Tests for correlation and regression analyses. Behav. Res. Methods 2009, 41, 1149-1160. [CrossRef]

48. Diamond, A. Executive Functions. Annu. Rev. Psychol. 2013, 64, 135-168. [CrossRef] [PubMed]

49. Schoene, D.; Valenzuela, T.; Toson, B.; Delbaere, K.; Severino, C.; Garcia, J.; Davies, T.A.; Russell, F.; Smith, S.T.; Lord, S.R. Interactive cognitive-motor step training improves cognitive risk factors of falling in older adultsA randomized controlled trial. PLoS ONE 2015, 10, e0145161. [CrossRef]

50. Schoene, D.; Lord, S.R.; Delbaere, K.; Severino, C.; Davies, T.A.; Smith, S.T. A Randomized Controlled Pilot Study of Home-Based Step Training in Older People Using Videogame Technology. PLoS ONE 2013, 8, e57734. [CrossRef] [PubMed]

51. Van het Reve, E.; de Bruin, E.D. Strength-balance supplemented with computerized cognitive training to improve dual task gait and divided attention in older adults: A multicenter randomized-controlled trial. BMC Geriatr. 2014, 14, 134. [CrossRef] [PubMed]

52. Kayama, H.; Okamoto, K.; Nishiguchi, S.; Yukutake, T.; Tanigawa, T.; Nagai, K.; Yamada, M.; Aoyama, T. Efficacy of an Exercise Game Based on Kinect in Improving Physical Performances of Fall Risk Factors in Community-Dwelling Older Adults. Games Health J. 2013, 2, 247-252. [CrossRef] [PubMed]

53. Cho, K.H.; Lee, K.J.; Song, C.H. Virtual-Reality Balance Training with a Video-Game System Improves Dynamic Balance in Chronic Stroke Patients. Tohoku J. Exp. Med. 2012, 228, 69-74. [CrossRef]

54. Rendon, A.A.; Lohman, E.B.; Thorpe, D.; Johnson, E.G.; Medina, E.; Bradley, B. The effect of virtual reality gaming on dynamic balance in older adults. Age Ageing 2012, 41, 549-552. [CrossRef]

Publisher's Note: MDPI stays neutral with regard to jurisdictional claims in published maps and institutional affiliations.

(C) 2020 by the authors. Licensee MDPI, Basel, Switzerland. This article is an open access article distributed under the terms and conditions of the Creative Commons Attribution (CC BY) license (http://creativecommons.org/licenses/by/4.0/). 